\title{
Cone beam CT of the musculoskeletal system: clinical applications
}

\author{
Magdalena Posadzy $^{1}$ - Julie Desimpel ${ }^{2,3} \cdot$ Filip Vanhoenacker ${ }^{2,3,4}$
}

Received: 13 June 2017 /Revised: 8 November 2017 / Accepted: 20 November 2017 /Published online: 4 January 2018

(C) The Author(s) 2018. This article is an open access publication

\begin{abstract}
Objectives The aim of this pictorial review is to illustrate the use of CBCT in a broad spectrum of musculoskeletal disorders and to compare its diagnostic merit with other imaging modalities, such as conventional radiography (CR), Multidetector Computed Tomography (MDCT) and Magnetic Resonance Imaging.

Background Cone Beam Computed Tomography (CBCT) has been widely used for dental imaging for over two decades. Discussion Current CBCT equipment allows use for imaging of various musculoskeletal applications. Because of its low cost and relatively low irradiation, CBCT may have an emergent role in making a more precise diagnosis, assessment of local extent and follow-up of fractures and dislocations of small bones and joints. Due to its exquisite high spatial resolution, CBCT in combination with arthrography may be the preferred technique for detection and local staging of cartilage lesions in small joints. Evaluation of degenerative joint disorders may be facilitated by CBCT compared to CR, particularly in those anatomical areas in which there is much superposition of adjacent bony structures. The use of CBCT in evaluation of
\end{abstract}

Magdalena Posadzy

magdalenaposadzy@gmail.com

Department of Radiology, W. Dega Orthopaedic and Rehabilitation University Hospital of Karol Marcinkowski University of Medical Sciences, Poznan, Poland

2 Department of Radiology, Antwerp University Hospital, Antwerp University, Antwerp, Belgium

3 Department of Radiology, AZ Sint-Maarten, Mechelen, Belgium

4 Faculty of Medicine and Health sciences, Ghent University, Ghent, Belgium osteomyelitis is restricted to detection of sequestrum formation in chronic osteomyelitis. Miscellaneous applications include assessment of (symptomatic) variants, detection and characterization of tumour and tumour-like conditions of bone.

Teaching Points

- Review the spectrum of MSK disorders in which CBCT may be complementary to other imaging techniques.

- Compare the advantages and drawbacks of CBCT compared to other imaging techniques.

- Define the present and future role of CBCT in musculoskeletal imaging.

Keywords Cone beam computed tomography $\cdot$ Multidetector computed tomography $\cdot$ Conventional radiography $\cdot$ Magnetic resonance imaging $\cdot$ Musculoskeletal imaging

$\begin{array}{ll}\text { Abbreviations } \\ \text { CBCT } & \text { Cone Beam Computed Tomography } \\ \text { CBCT-A } & \text { Cone Beam Computed Arthrography } \\ \text { CR } & \text { Conventional Radiography } \\ \text { FOV } & \text { Field of View } \\ \text { HU } & \text { Hounsfield Units } \\ \text { kVp } & \text { KiloVoltage power } \\ \text { mAs } & \text { Milliamperage seconds } \\ \text { MDCT } & \text { Multidetector Computed Tomography } \\ \text { MRI } & \text { Magnetic Resonance Imaging }\end{array}$

\section{Introduction}

Although initially used for dental imaging, Cone Beam Computed Tomography (CBCT) is currently installed in many radiology departments as an integral part of the imaging armamentarium. CBCT uses a conical x-ray beam 
which falls on a flat panel detector unlike conventional Multidetector Computed Tomography (MDCT), where a fan shaped beam and linear detectors are used (Fig. 1). In $\mathrm{CBCT}$, the X-ray tube and the detector synchronously rotate $360^{\circ}$ around the patient. At certain degree intervals, single projection images or "basis" images, are acquired. Software programs incorporating sophisticated algorithms including back-filtered projection are applied to these projection data to generate a volumetric data set, which can be used for reconstruction images in three orthogonal planes [1]. In our department, we use a CBCT with a gantry of $58 \mathrm{~cm}$ patient aperture and a movable table allowing horizontal positioning and multifunctional use (NewTom $5 \mathrm{G}$, QR systems, Verona, Italy). The specific purpose of this paper is to present a pictorial overview of the clinical usefulness of the CBCT of evaluation in a broad spectrum of musculoskeletal disorders and to compare its diagnostic merit with other imaging modalities, such as conventional radiography (CR), Multidetector Computed Tomography (MDCT) and Magnetic Resonance Imaging (MRI).
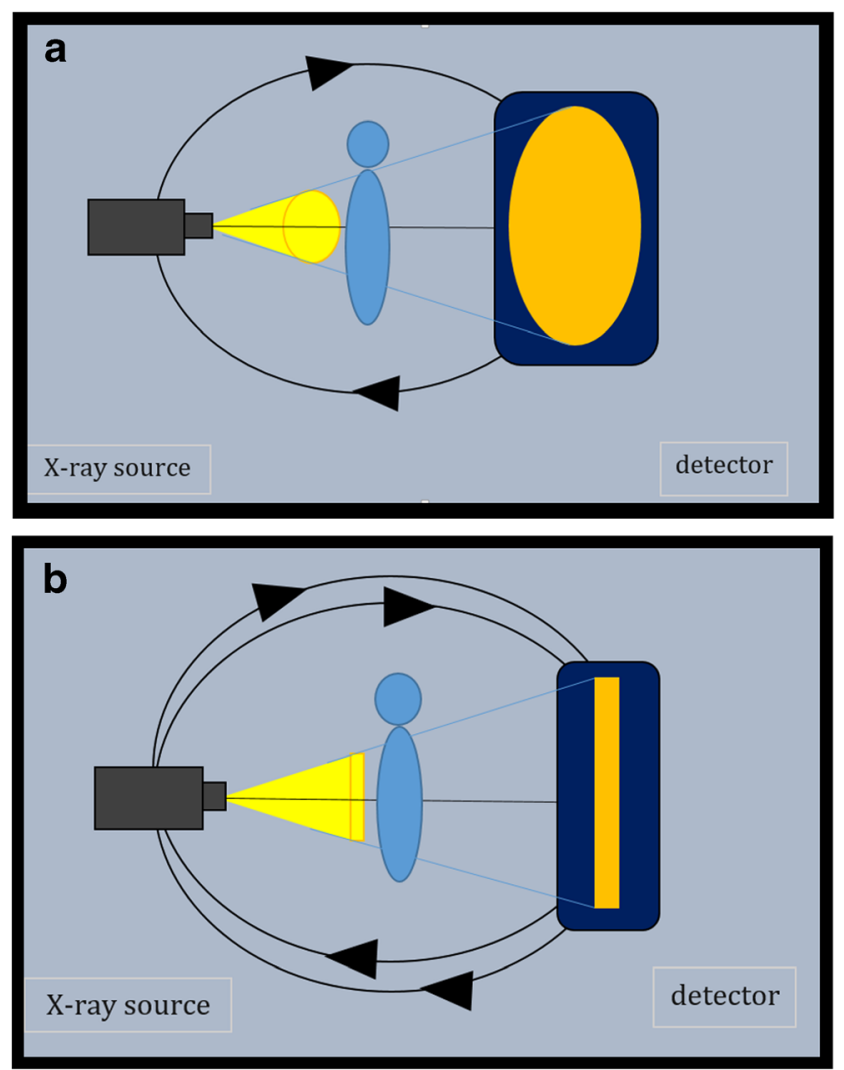

Fig. 1 Principle of CBCT and MDCT. a In CBCT, cone-shaped X-ray beam reaches a flat detector after a single rotation of the gantry around the patient. b In MDCT, narrowly collimated, fan-shaped beam and multiple linear detectors rotate around the patient to acquire multiple image sections per rotation. In both techniques volumetric images are reconstructed into a 3-D volume dataset of images

\section{Advantages and disadvantages}

A major advantage of $\mathrm{CBCT}$ is its high spatial resolution resulting in exquisite detail of bone microarchitecture (Fig. 2a) $[2,3]$. CBCT after intra-articular contrast injection (CBCT arthrography; CBCT-A) offers high resolution images of the articular cartilage surface. (Fig. 2b) [4]. With our equipment, the spatial resolution ranges between $300 \mu \mathrm{m}$ for a standard scan to $75 \mu \mathrm{m}$ for high resolution images. Recent studies, performed on phantoms and also in a cohort of paediatric patients, confirm the significant lower dose of CBCT, compared to MDCT [5-11]. Effective dose for paranasal sinuses imaging in CBCT is approximately $40 \%$ lower than standard MDCT and 30\% lower than low-dose sinus CT scans [12]. Studies on phantoms in the ankle region showed $21.4 \mu \mathrm{Sv}$ of effective dose for MDCT, for CBCT it was reported ranging from $1.9 \mu \mathrm{Sv}$ to $14.3 \mu \mathrm{Sv}$ [11]. Lower radiation dose results from single rotation of the gantry required for acquisition of the whole scan volume, smaller field of view, pulsed X-ray beams instead of the constant radiation stream and the use of a large high quality flat panel detector [13].
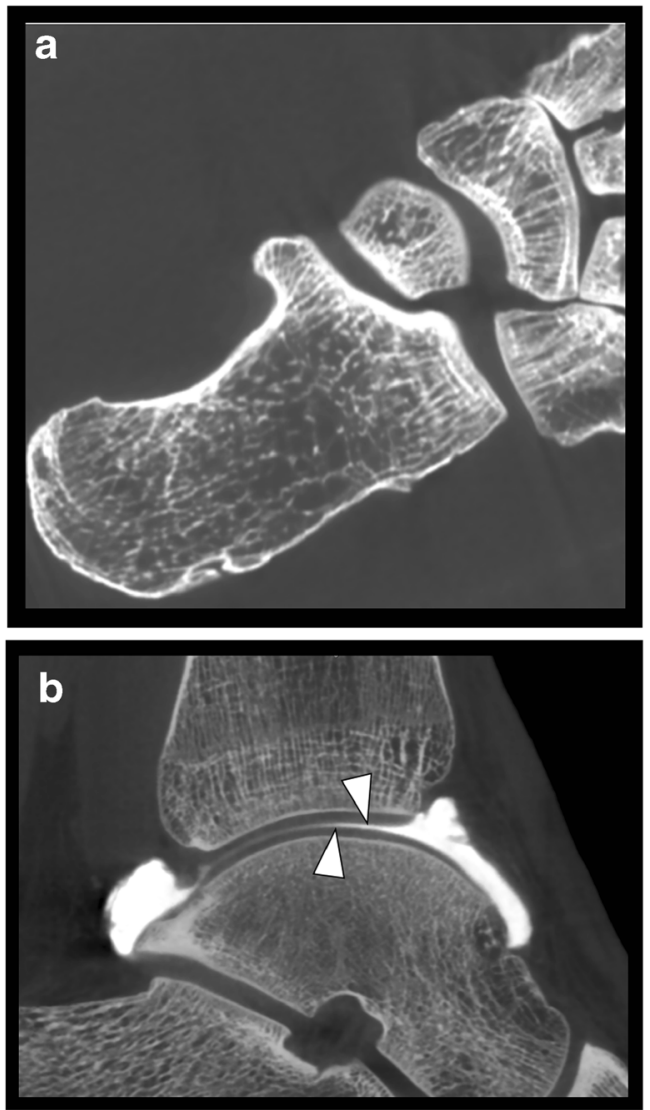

Fig. 2 Evaluation of bone architecture and normal articular cartilage. a. Axial CBCT image of a cadaver foot illustrating exquisite detail of the cortical and trabecular bone architecture. b. Sagittal reformatted image of a CBCT-A of the talocrural joint showing smooth surface of normal articular cartilage surface of distal tibia and talar dome (arrowheads) 
Table 1 Comparison of parameters influencing the economic rentabilty of $\mathrm{CBCT}$ versus MDCT

\begin{tabular}{|c|c|c|}
\hline & CBCT (high-end) & MDCT (mid-end) \\
\hline Purchase price equipment* & $21-30 \%$ (200,000 Euro) & $(665,000-968,000$ Euro $)$ \\
\hline Annual maintenance service* & $10 \%(10,000$ Euro $)$ & $(100,000$ Euro $)$ \\
\hline $\begin{array}{l}\text { Required area for placement } \\
\text { of equipment }+ \text { operating } \\
\text { space for medical staff } \\
\text { (minimum versus our hospital) }\end{array}$ & $16.5 \mathrm{~m}^{2}-33 \mathrm{~m}^{2}$ & $36 \mathrm{~m}^{2}-52 \mathrm{~m}^{2}$ \\
\hline Investment cost for room preparation & 100,000 Euro & 150,000 Euro \\
\hline $\begin{array}{l}\text { Operating cost } \\
\text { (electricity, other utilities) }\end{array}$ & $50 \%$ & $100 \%$ \\
\hline Cost medical staff & $\begin{array}{l}\text { Similar (10 min acquisition } \\
\text { and reconstruction time) }\end{array}$ & $\begin{array}{l}\text { Similar (10 min acquisition } \\
\text { and reconstruction time) }\end{array}$ \\
\hline Honorarium examination & $\begin{array}{l}\text { Similar (e.g. } 50.90 \text { Euro for } \\
\text { MSK examination)** }\end{array}$ & Similar (e.g. 50.90 Euro for MSK) \\
\hline $\begin{array}{l}\text { Other applications than small } \\
\text { bones/joints }\end{array}$ & Dental, petrous bone, sinuses & $\begin{array}{l}\text { Brain, Spine, Abdomen, Chest, Bone } \\
\text { and Joints (including large joints), } \\
\text { CT-angiography, ... }\end{array}$ \\
\hline
\end{tabular}

*Based on list price provided by the manufacturer of our high-end CBCT equipment versus a MDCT mid-end equipment (range of different manufacturers)

**Currently pending approval of the National Institute for Sickness and Invalidity Insurance of our country Abbreviations: $\mathrm{m}=$ meter; $\mathrm{m}^{2}=$ square meter; $\mathrm{MSK}=$ musculoskeletal; $\%=$ percentage

Our NewTom $5 \mathrm{G}$ equipment uses a fixed tube voltage of $110 \mathrm{kVp}$, but is fitted with the SafeBeam technology allowing reduction of the radiation dose.

Initial optimization of the tube current $(\mathrm{mA})$ occurs on estimation of the patient size based on the attenuation information derived from an anteroposterior and lateral scout views [11].

Angular tube current modulation further equalizes in real time the photon flux to the detector as the X-ray tube rotates about the patient among the anteroposterior and lateral position according to the measured attenuation from the previous projection, allowing further adaptation of the dose for the anatomy of the patient $[14,15]$.

By using the pulsed emission technology, exposure is restricted to intermittent bursts of radiation for each degree instead of using a constant stream of radiation during the 360 ${ }^{\circ}$ rotation. This results in a considerable decrease of effective exposure time (e.g., if a $360^{\circ}$ rotation lasts for 18 to $36 \mathrm{~s}$, the effective exposure time during the $360^{\circ}$ rotation is 2.4 to $7.3 \mathrm{~s}$ ) [16]. This does not affect the overall image quality as the dataset obtained from 360 projections (one for each degree during $360^{\circ}$ rotation) may be used for qualitative image reconstruction.

For small joints, the spectrum of the effective dose (ED) in CBCT ranges between 1 to $15.3 \mu \mathrm{Sv}$ applying a conversion

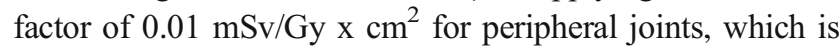
significantly lower than values reported for MDCT. Among those imaging methods using radiation, Conventional Radiography (CR) still remains the one with the lowest ED, between 0.07 to $5 \mu \mathrm{Sv}$ ) [17].
Table 2 Advantages and disadvantages of musculoskeletal CBCT

\begin{tabular}{ll}
\hline ADVANTAGES & DISADVANTAGES \\
\hline $\begin{array}{l}\text { Lower radiation dose than MDCT } \\
\text { More comfortable positioning than } \\
\text { MRI for patients suffering from } \\
\text { claustrophobia }\end{array}$ & $\begin{array}{l}\text { Radiation exposure higher than CR } \\
\text { Prone to motion artifacts } \\
\text { (patient with tremor, children) }\end{array}$ \\
$\begin{array}{l}\text { Suitable for postoperative follow-up } \\
\text { in patient with metallic implants } \\
\text { using appropriate metal artifact algorithms }\end{array}$ & $\begin{array}{c}\text { Limited field of view } \\
\text { High spatial resolution images of } \\
\text { bone architecture }\end{array}$ \\
$\begin{array}{l}\text { High spatial resolution images of cartilage } \\
\text { surface after intra-articular contrast injection }\end{array}$ & $\begin{array}{c}\text { Limited evaluation of soft } \\
\text { tissue pathology }\end{array}$ \\
$\begin{array}{l}\text { Relative low cost of equipment } \\
\text { Joint imaging in weight-bearing position } \\
\text { with some CBCT equipment }\end{array}$ & Mildly more time consuming than CR, \\
comparable examination time to \\
\end{tabular}



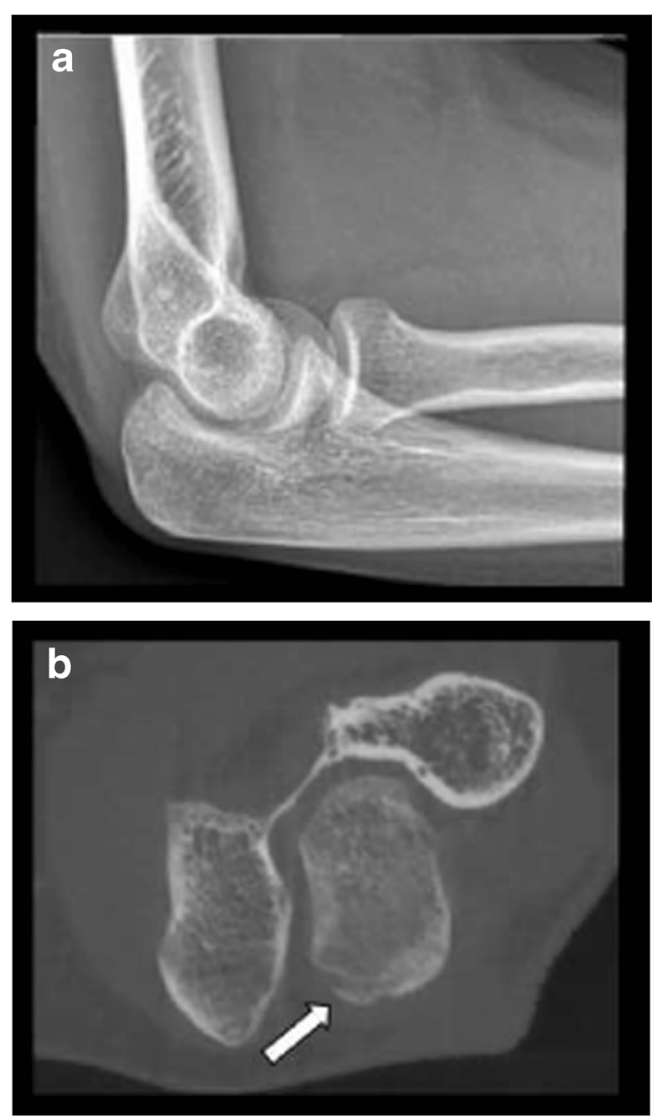

Fig. 3 Occult olecranon fracture. a. Lateral view $\mathrm{CR}$ of the elbow shows no evidence of fracture. b. Axial CBCT reformatted image reveals subtle cortical disruption and a small adjacent bone fragment at the posterior aspect of the olecranon process

However, image quality of $\mathrm{CT}$ and $\mathrm{CBCT}$ images may be altered by implanted metal elements reducing the contrast, obscuring structures and impairing the detection of areas of interest. This image degradation may be reduced by using dedicated algorithms and software $[18,19]$. The overall cost of the equipment is far less than MDCT [20], thus it is suited for private practices or small medical centres or as additional CT equipment in large institutions. Table 1 provides a short overview of the parameters that may influence the economic rentability of installing a CBCT. However, as the referral pattern for certain examinations may differ among different health care centres and reimbursement can significantly differ depending on the health policy of each country, it is not possible to provide general recommendations.

A disadvantage of CBCT is the limited field of view (FOV), which ranges from $6 \times 6 \mathrm{~cm}$ to maximum $18 \times$ $16 \mathrm{~cm}$ with our equipment. Therefore, $\mathrm{CBCT}$ is not suitable for imaging of large joints. Another drawback is its limitation to assess soft tissue pathology due to lack of contrast resolution and Hounsfield Units (HU) measurements. Furthermore, $\mathrm{CBCT}$ is more time consuming (18 to $36 \mathrm{~s}$ of acquisition time) resulting in higher susceptibility to motion artifacts. Table 2
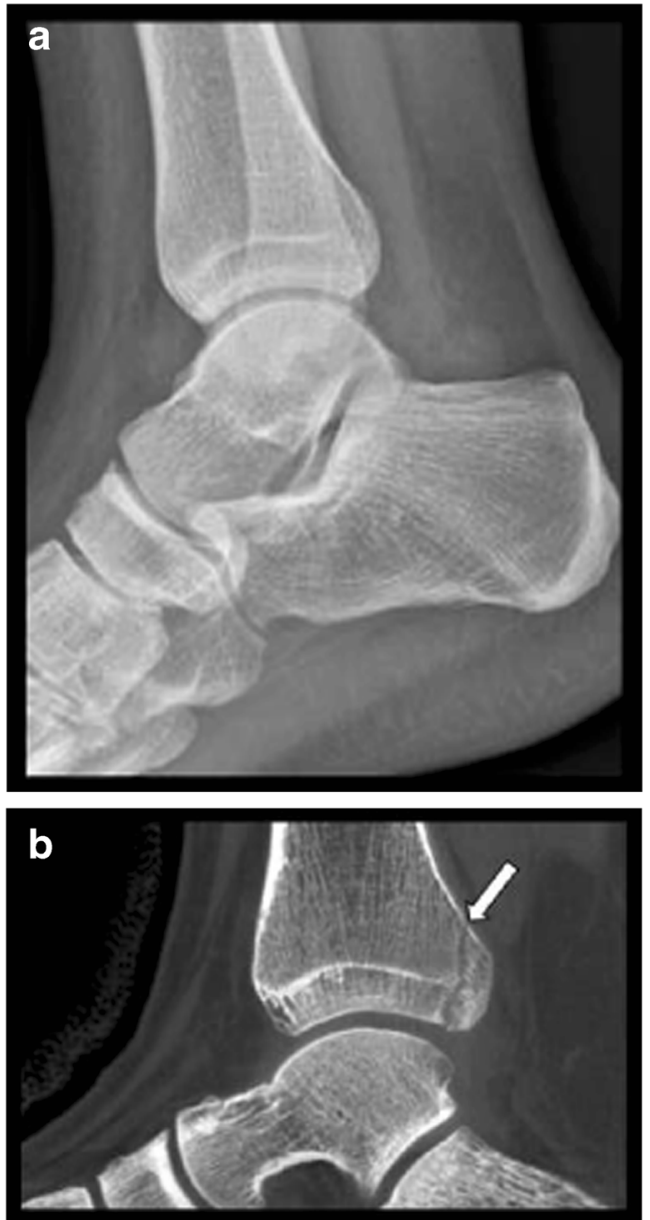

Fig. 4 Fracture of the posterior malleolus in a 16-year-old female. a. CR (lateral view) of the ankle shows no evidence of fracture. b. Sagittal CBCT reconstruction showing a non-displaced malleolus tertius fracture (arrow). CBCT clearly demonstrates intra-articular extension of the fracture

summarizes the main advantages and disadvantages of musculoskeletal CBCT.

\section{Evaluation of fractures, dislocations and their follow-up}

$\mathrm{CR}$ is the first-line imaging technique in case of clinical suspicion of fractures, although being less sensitive than crosssectional imaging. CBCT imaging shows higher sensitivity in detection of small bone and joint trauma than $\mathrm{CR}$ and may visualize fractures being occult on CR (Fig. 3 and Fig. 4) or confirm doubtful fractures [17, 21, 22]. In most cases, this has an impact on the treatment strategy [5]. Comparison of MDCT as the gold standard with $\mathrm{CBCT}$ for finger fractures showed similar results in depicting the fracture and assessment of articular involvement [7]. In case of high clinical suspicion of carpal fractures (especially the scaphoid bone), but negative $\mathrm{CR}$, subsequent MRI is often recommended for exclusion of 
Fig. 5 Complex fracture of the dorsal side of the styloid process of the radius with intra-articular involvement, multiple intraarticular fracture fragments and perilunate dislocation. a. CR (oblique view) shows a fracture of the distal radius (arrowhead) and perilunate dislocation (arrow). b. Sagittal CBCT reformatted image after immobilization and casting (stars) shows residual perilunate dislocation (white arrow) with dorsal displacement of the distal carpal row and additional fracture fragments (arrowhead). c. Coronal CBCT reformatted image after immobilization and casting (stars) demonstrates distal radius fracture (black arrow). The degree of communition and additional fracture fragments better seen than on plain films (arrowhead). d. 3-D reconstruction may be useful for evaluation of the displacement of the carpal bones (open arrow) and additional fracture fragments (open arrowhead)
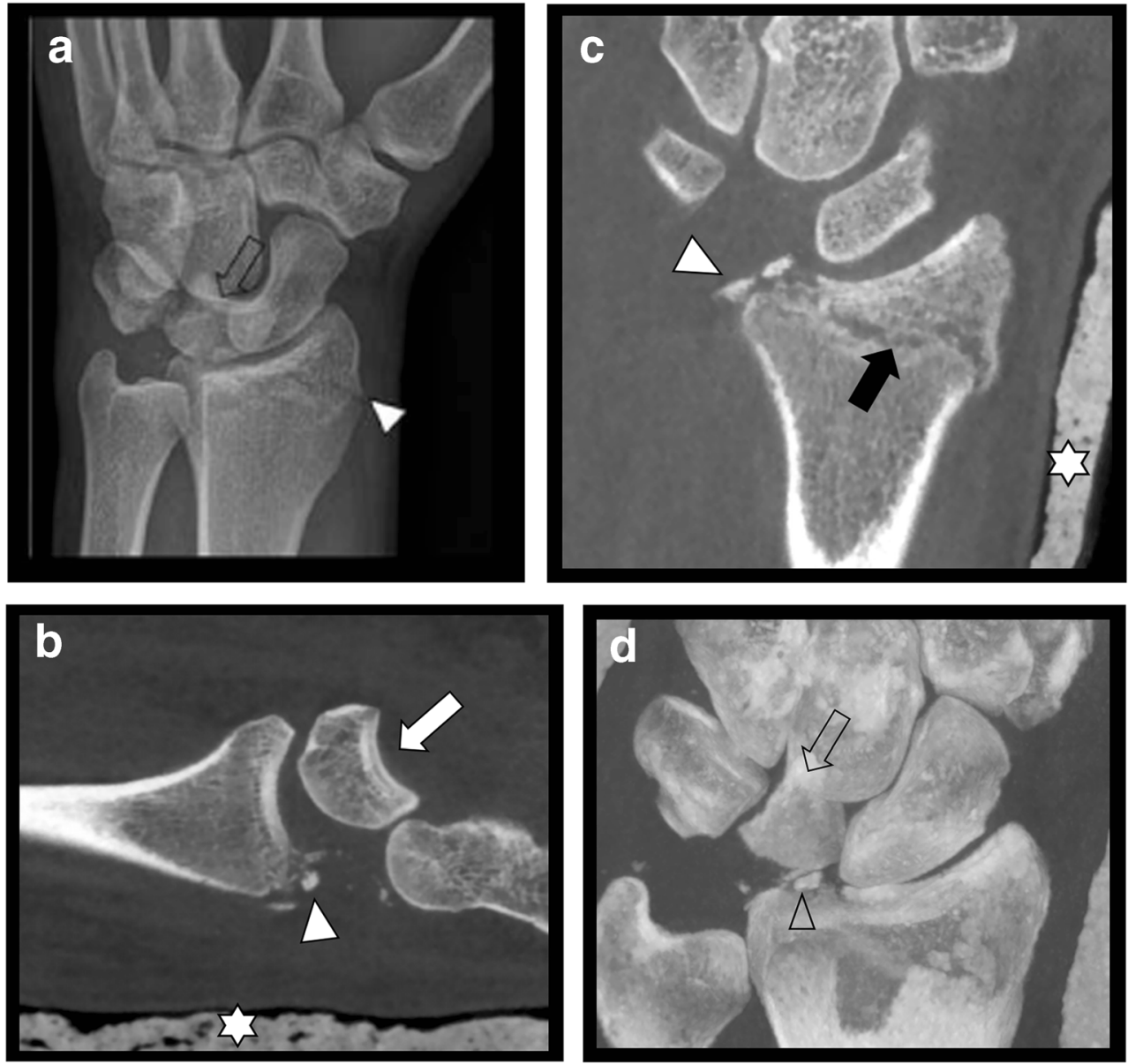

occult nondisplaced fractures and bone marrow contusion. In this scenario, MRI remains more sensitive than CBCT [21]. Nonetheless, it is not always possible to perform MRI immediately following trauma and MRI cannot be performed in every patient, due to potential contraindications or lesser accessibility. Therefore, CBCT should be considered as a second line imaging modality in assessing complex anatomical sites with multiple overlapping bones, such as the wrist (Fig. 5) and foot, in case of negative CR but with high clinical suspicion of a fracture. Prompt, accurate evaluation of fractures may obviate the need of MRI at a later date [21] .

In case of suspicion of joint instability, weight-bearing CBCT provides information about joint alignment $[5,8]$ although this can only be performed on dedicated CBCT equipment [20].

For follow-up of bone healing and callus formation, CR may be difficult, especially in the presence of overlying splints or casts. As CBCT can provide more detailed information on bone architecture in comparison to $\mathrm{CR}$, it can also help in evaluation of the healing process, which can be over- or underestimated on CR [6]. As a cross-sectional technique and the possibility for multidirectional reformations and 3-D reconstructions, $\mathrm{CBCT}$ is superior to $\mathrm{CR}$ in assessment of callus formation, osseous bridging and evaluation of residual fracture lines. In case of postoperative follow-up after placement of metallic hardware, incomplete healing as well as early detection of hardware loosening may be facilitated by CBCT. For hardware fractures, however, CR still remains the preferred method because of potential metallic streak artifacts on CBCT. The possible explanation for this potential discrepancy is related to the size of the metal objects. Indeed, at the bone-screw interface, higher contrast and spatial resolution of CBCT dominates the effect of the beam hardening owing to the relatively small size of metallic screws. Conversely, the beam hardening artifact surrounding large side plates in CBCT images compared with plain radiograph dominates the effect of better contrast resolution on CBCT [23]. Despite the use of current Metal Artifact Reduction sequences, the overall usefulness of MRI after screw fixation is limited due to metal artifacts.

\section{Bone tumours and tumour-like lesions}

The value of CBCT in the assessment of tumour and tumourlike conditions of the jaw bones has been reported previously 

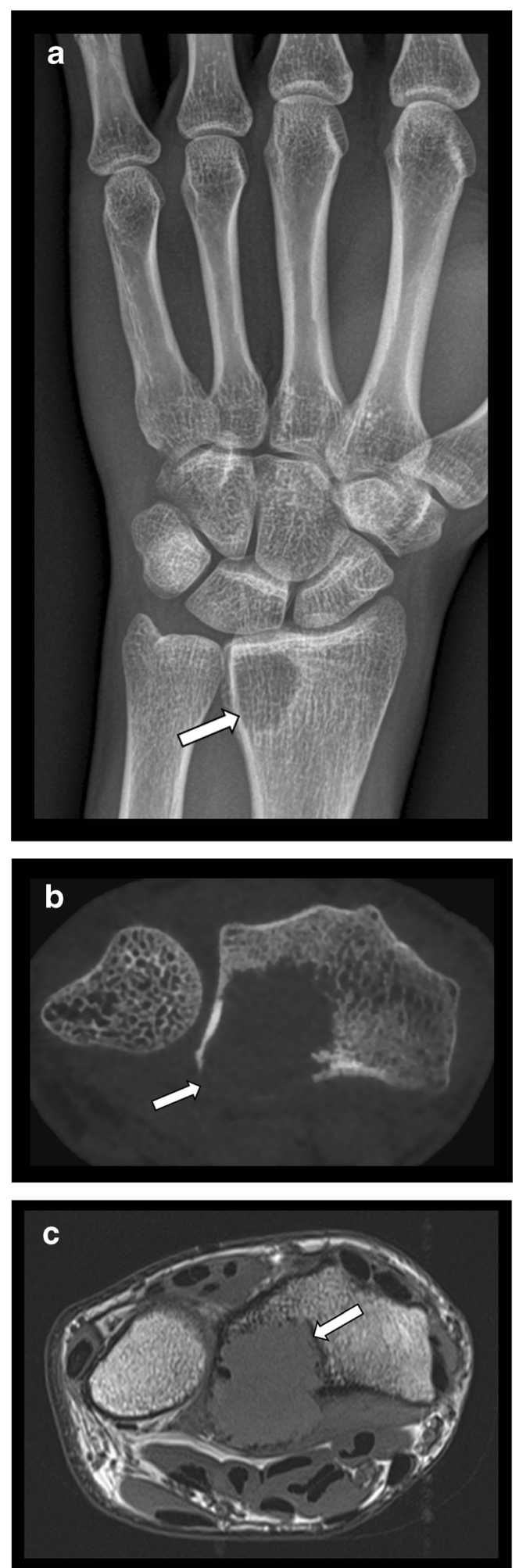

Fig. 6 Giant cell tumour of distal radius. a. CR (AP view) showing an osteolytic lesion in the distal epiphysis of the radius (arrow). There is no major cortical breakthrough visible on CR. b. Axial CBCT reconstruction clearly show cortical breakthrough of the lesion. The precise extent of the soft tissue involvement is inaccurate due to insufficient soft tissue contrast. c. On axial T1-WI MRI, the lesion is isointense to muscle with cortical disruption at the volar aspect and involvement of pronator quadratus muscle. MRI is far superior for evaluation of the soft tissue component of the lesion
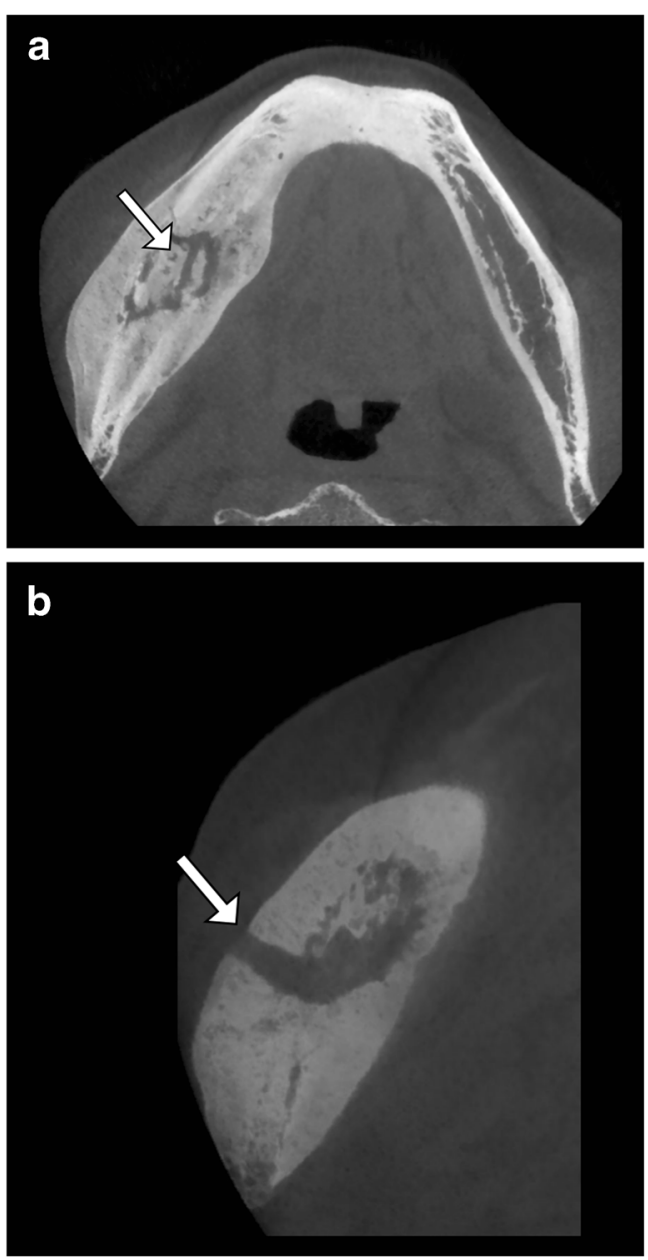

Fig. 7 Chronic osteomyelitis of the right hemimandible. a. Axial CBCT reformatted image showing chronic osteomyelitis of the right hemimandible with intralesional sequestrum (arrow). Note marked sclerosis of the right hemimandible compared to the left side and massive periosteal bone reaction (involucrum). b. Detailed axial view shows the course of a fistula through the mandibular cortex to the buccal soft tissues (arrow)

in the dental literature [24-26]. Compared to the limited 2dimensional information of conventional panoramic view, CBCT provides more precise information on location, morphology, intra-osseous extent, cortical breakthrough periosteal reaction and local effect on adjacent structures and teeth roots. Although definitive characterization of these lesions is often difficult or even impossible due to overlapping imaging characteristics, analysis of the matrix and intralesional calcifications and relationship with dentition are very helpful parameters in identification of odontogenic and non- odontogenic tumour and tumour-like conditions of the jaws. A disadvantage of CBCT is its limited assessment of the potential soft tissue component of the lesions. For bone tumours located in extremities, the use of CBCT is less documented. Similar to lesions in the jaws, CBCT allows for a more accurate evaluation of lesion location (either in the longitudinal or transverse 

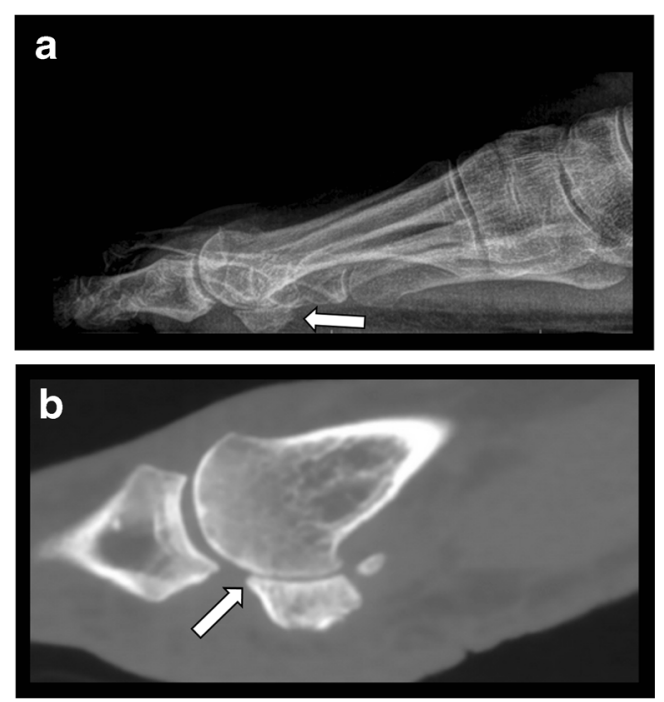

Fig. 8 Sesamoid degenerative changes. a. CR lateral view of the foot in standing position with suspected degenerative changes between the sesamoids and the first metatarsal head. b. CBCT sagittal reformatted image shows osteophyte formation, narrowing of the joint space and subchondral sclerosis at the joint between the plantar aspect of the metatarsal head and the medial sesamoid (arrow)

axis of the bone), cortical breakthrough and periosteal reaction than CR (Fig. 6). Although these semiological features may help in lesion characterisation, MDCT and especially MRI are better suited for evaluation of the soft tissue component. Therefore, CBCT cannot be regarded as preferred technique for assessment of bone tumours.

\section{Osteomyelitis}

Although the preferred imaging modalities in evaluation of osteomyelitis are $\mathrm{CR}$ as baseline examination for follow-up and MRI for early detection and staging, CT is the best technique for assessment of a sequestrum in chronic osteomyelitis (Fig.7). In the jaw bones and appendicular skeleton, CBCT may have an equal diagnostic performance as MDCT. On MRI, a sequestrum is difficult to distinguish from sclerotic but viable bone. CBCT can also provide more detailed visualization of osteolytic changes caused by infection in the presence of metallic hardware.

\section{Degenerative joint disease}

In comparison to $\mathrm{CR}, \mathrm{CBCT}$ shows more precisely the degree and extent of degenerative joint changes. It can depict pathology in small joints not visible due to overlying of bony structures, for example, in sesamoid bones at the level of metatarsal head (Fig.8) or in the presence of a metallic screw (Fig.9). Small osteophytes, joint space narrowing and subtle areas of subchondral sclerosis can be detected. Evaluation of this
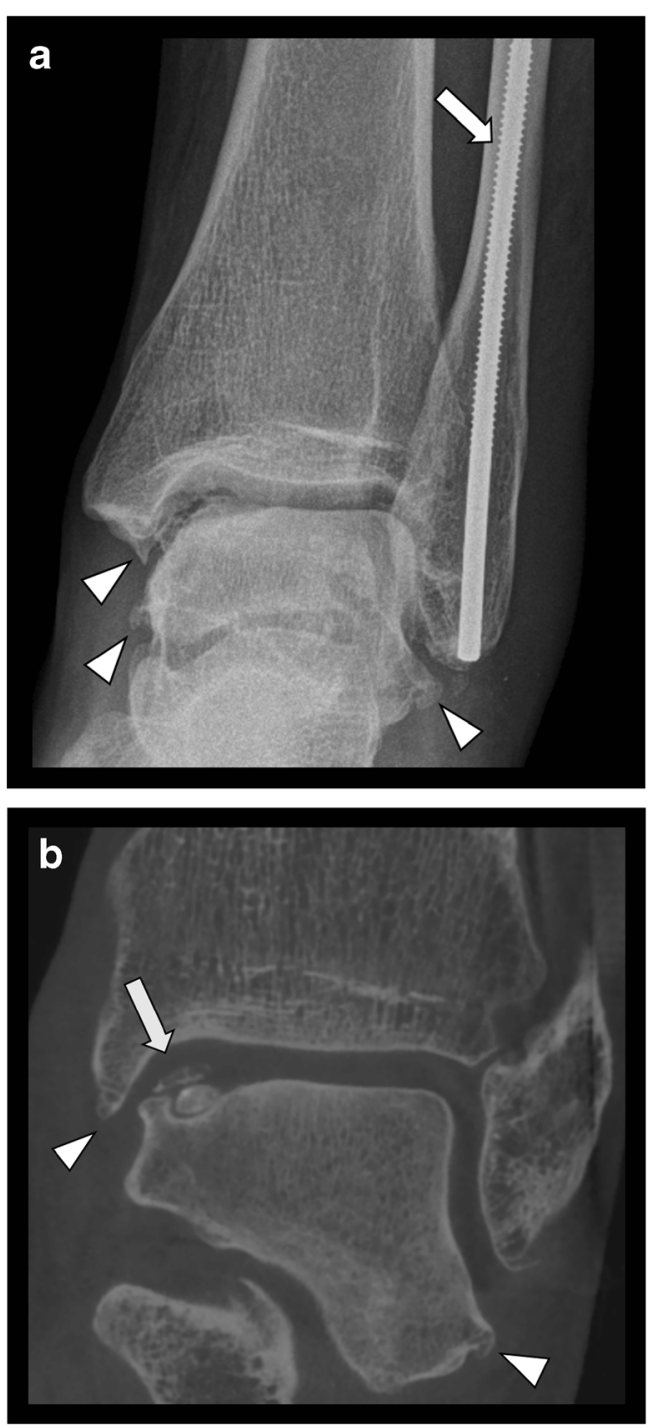

Fig. 9 Posttraumatic unstable osteochondral lesion of the talus and massive degenerative changes of the ankle in a 66-year-old female. a. $\mathrm{CR}$ (AP view) demonstrating the presence of metallic screw within the fibula (arrow). Note irregular articular surface of talar dome and advanced degenerative changes with osteophytes formation (arrowheads). b. CBCT coronal reformatted image better shows the presence and extent of an unstable osteochondral lesion (arrow) and osteophytes (arrowheads). There is no metal artifact from the screw in the fibula

subtle cartilage loss in small joints on MRI is far more challenging because of poor spatial resolution. However, bone marrow oedema indicating disease activity is only detected on MRI.

\section{CBCT arthrography}

To evaluate chondral lesions, arthroscopy is a reference standard procedure offering also simultaneous treatment. Considering the operative risk and invasive nature of 

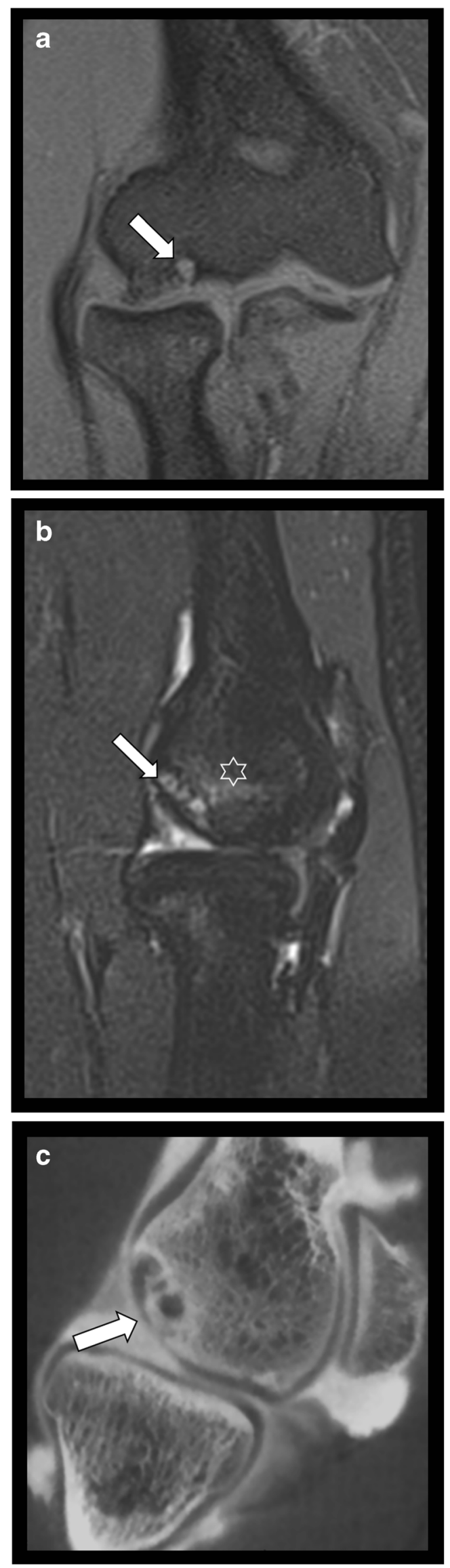

4 Fig. 10 Osteochondral lesion of the capitulum. a. Coronal T1-WI fat saturated MR image showing a osteochondral lesion of the capitulum. b. Sagittal PD MRI fat saturated image at the level of radio-humeral joint revealing subchondral bone marrow changes (star) and subchondral cyst formation (arrow), the cartilage cannot be evaluated precisely. c. Sagittal reformatted CBCT-A at the level of the radio-humeral joint showing the osteochondral lesion of the capitulum with subchondral cyst formation, surrounding sclerosis and subtle focal thinning of the articular cartilage (arrow)

arthroscopy, appropriate preoperative imaging is preferable for diagnosis and local staging of cartilage lesions. For some cartilage lesions MR-arthrography (MRA) is widely used, particularly at the wrist. CBCT arthrography has -however- a better spatial resolution, the ability for thin multiplanar reformats allowing more accurate staging of articular cartilage lesions (Fig.10). This method can be notably useful in case of orthopaedic implants located near the area of interest [9, 27], in which MRI is less feasible due to susceptibility artifacts [27]. Intra-articular loose bodies (Fig. 11) or synovial tumour and tumour-like conditions such as Pigmented Villonodular Synovitis (PVNS) can be also better visualized after intra-articular contrast injection (Fig. 12).

\section{Miscellaneous}

Another useful application of CBCT is the imaging of various anatomic variants, bony coalitions, osseous defects simulating cartilage lesions on other imaging modalities (Fig. 13) or accessory or bifid bones (Fig.14).

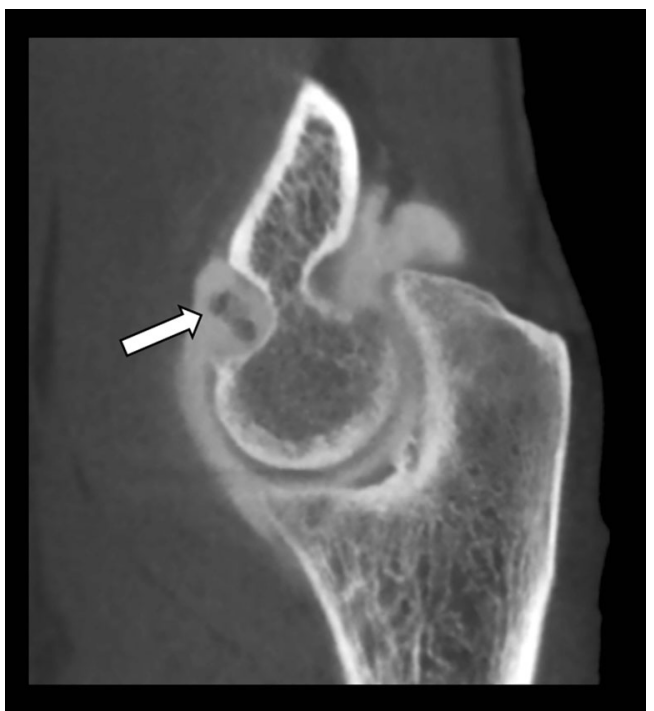

Fig. 11 Intra-articular loose bodies. Sagittal CBCT-A reformatted image shows the presence of intra-articular loose bodies (arrow) 

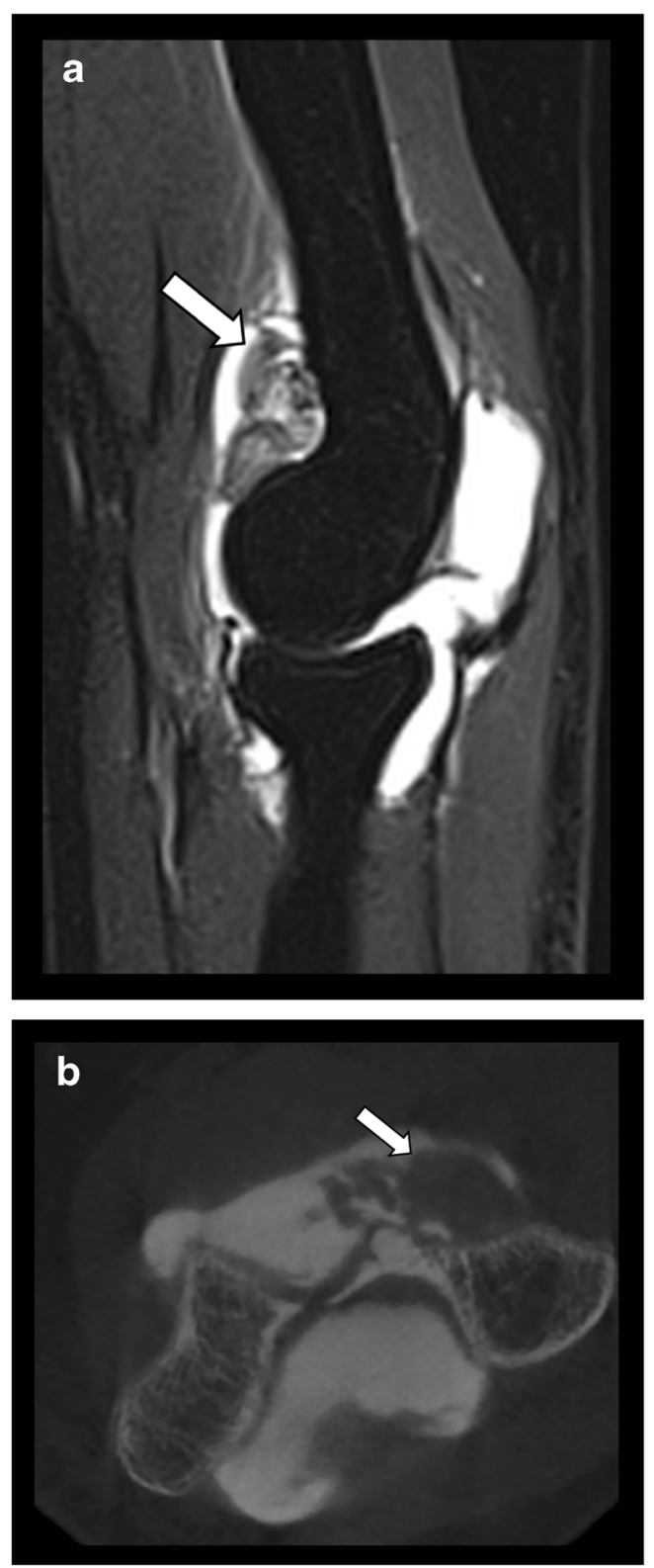

Fig. 12 Pigmented villonodular synovitis of the elbow. a. Sagittal T2WI fat suppressed MRI image presenting a mass within the joint cavity (arrow) with a low signal areas related to hemosiderin deposits. b. CBCTA showing the presence of proliferative synovium (arrow) within the anterior part of the joint cavity

\section{Interventional radiology and future developments}

Some modern flat panel detector $\mathrm{C}$-arm units combine fluoroscopy with $\mathrm{CBCT}$ imaging offering guidance for interventional radiology procedures [28]. Spinal interventions including nucleoplasty, vertebroplasty or bone biopsies are among the most frequently performed percutaneous interventional musculoskeletal procedures. More and more ablation or palliative procedures are performed under imaging guidance, including CBCT [29]. When precise biopsy needle positioning is difficult to achieve, CBCT application can help in choosing
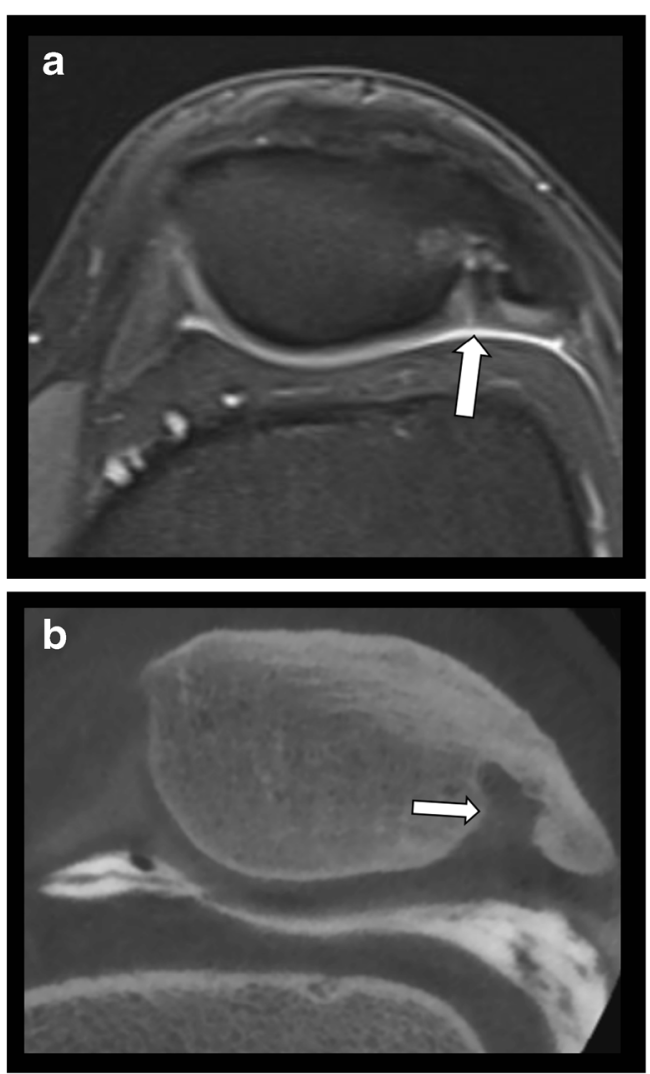

Fig. 13 Dorsal defect of the patella simulating a large cartilage defect on MRI. a. Axial T2 WI fat saturated MR image shows a focal bony defect with surrounding bone marrow edema at the superolateral aspect of the patella. There is suspicion of an overlying cartilage fissure (arrow). b. Axial reformatted CBCT-A demonstrates a dorsal patella defect. The overlying patellar cartilage is intact.

the best approach, precise tracking and detection of errors in the operating room. The reduction of cumulative dose to

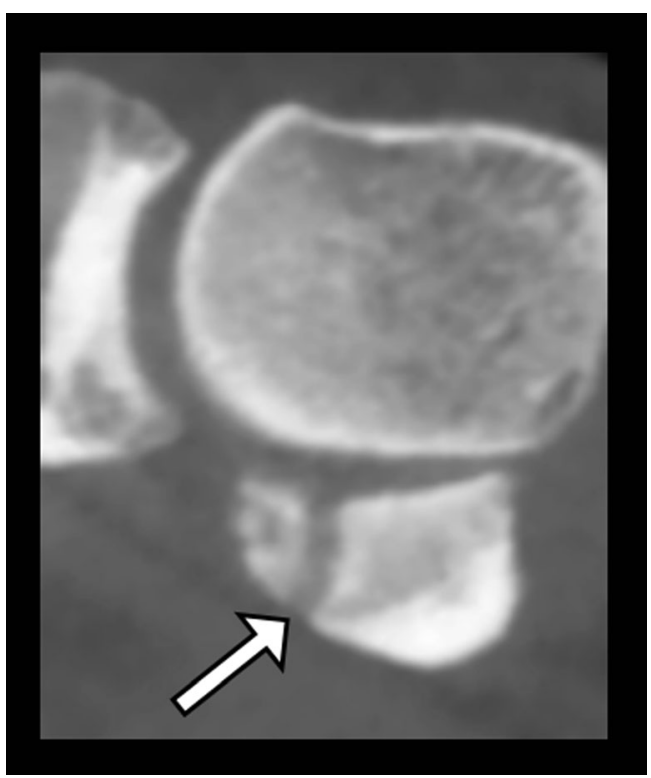

Fig. 14 Bifid medial sesamoid bone of the hallux. Sagittal reformatted $\mathrm{CBCT}$ demonstrating the presence of this anatomical variant (arrow) 
patient and staff can be achieved by reduction of fluoroscopy time due to the usage of CBCT guidance [28, 30]. Fusion with MRI for precise lesion targeting has been reported as well [31]. The overall duration of those procedures under MDCT and CBCT guidance are similar with less dose applied to both the patient and performing physician for CBCT [32]. Especially in young patients, lower radiation dose is of utmost importance. Other systems on the market are designed for weight-bearing extremities examinations, allowing evaluation of joint stability [20]. Given the specific design (the size of the gantry, presence of guide lights for needle position) for each application, every business case for purchasing CBCT equipment should be tailored to the special needs in each department.

\section{Conclusions}

CBCT is a promising method that may be very useful for evaluation of trauma of small joints and bones, particularly when $\mathrm{CR}$ is negative or doubtful despite high clinical suspicion for fractures. In combination with arthrography, CBCT offers high anatomical detail of articular cartilage, which may be an advantage to routine MRI in evaluation of osteochondral lesions in joints with thin cartilage such as the ankle joint. Furthermore, the technique may serve as an alternative method to MRI for a variety of musculoskeletal diseases in patients with claustrophobia or other contraindications of MRI. In all these scenarios, an improved diagnosis may result in a more timely and appropriate treatment regime. Although MDCT equipment remains the preferred $\mathrm{CT}$ technology for multifunctional purposes in most imaging departments, due to its low cost in purchase and maintenance, CBCT may be a useful tool in private practices with a high turn-over of musculoskeletal procedures or as an additional imaging tool to MDCT in large hospitals. Awareness of the advantages and disadvantages of the technique is a prerequisite for its dedicated use.

\section{Compliance with ethical standards}

Competing interests The authors have no competing interests.

Open Access This article is distributed under the terms of the Creative Commons Attribution 4.0 International License (http:// creativecommons.org/licenses/by/4.0/), which permits unrestricted use, distribution, and reproduction in any medium, provided you give appropriate credit to the original author(s) and the source, provide a link to the Creative Commons license, and indicate if changes were made.

\section{References}

1. Scarfe WC, Farman AG, Sukovic P (2006) Clinical applications of cone-beam computed tomography in dental practice. J Can Dent Assoc 72(1):75-80

2. Klintstrom E, Smedby O, Moreno R, Brismar TB (2014) Trabecular bone structure parameters from 3D image processing of clinical multi-slice and cone-beam computed tomography data. Skelet Radiol 43(2):197-204. https://doi.org/10.1007/s00256-0131766-5

3. Demehri S, Muhit A, Zbijewski W et al (2015) Assessment of image quality in soft tissue and bone visualization tasks for a dedicated extremity cone-beam CT system. Eur Radiol 25(6):17421751. https://doi.org/10.1007/s00330-014-3546-6

4. Ramdhian-Wihlm R, Le Minor JM, Schmittbuhl M et al (2012) Cone-beam computed tomography arthrography: an innovative modality for the evaluation of wrist ligament and cartilage injuries. Skelet Radiol 41(8):963-969. https://doi.org/10.1007/s00256-0111305-1

5. Pugmire BS, Shailam R, Sagar P et al (2016) Initial clinical experience with extremity cone-beam CT of the foot and ankle in pediatric patients. AJR Am J Roentgenol 206(2):431-435. https://doi. org/10.2214/AJR.15.15099

6. Huang AJ, Chang CY, Thomas BJ, MacMahon PJ, Palmer WE (2015) Using cone-beam CT as a low-dose 3D imaging technique for the extremities: initial experience in 50 subjects. Skelet Radiol 44(6):797-809. https://doi.org/10.1007/s00256-015-2105-9

7. Faccioli N, Foti G, Barillari M, Atzei A, Mucelli RP (2010) Finger fractures imaging: accuracy of cone-beam computed tomography and multislice computed tomography. Skelet Radiol 39(11):10871095. https://doi.org/10.1007/s00256-010-0911-7

8. Carrino JA, Al Muhit A, Zbijewski W et al (2014) Dedicated conebeam CT system for extremity imaging. Radiology 270(3):816824. https://doi.org/10.1148/radiol.13130225

9. Koskinen SK, Haapamaki VV, Salo J et al (2013) CT arthrography of the wrist using a novel, mobile, dedicated extremity cone-beam CT (CBCT). Skelet Radiol 42(5):649-657. https://doi.org/10.1007/ s00256-012-1516-0

10. Loubele M, Bogaerts R, Van Dijck E et al (2009) Comparison between effective radiation dose of CBCT and MSCT scanners for dentomaxillofacial applications. Eur J Radiol 71(3):461-468. https://doi.org/10.1016/j.ejrad.2008.06.002

11. Koivisto J, Kiljunen T, Kadesjo N, Shi XQ, Wolff J (2015) Effective radiation dose of a MSCT, two CBCT and one conventional radiography device in the ankle region. J Foot Ankle Res 8:8. https:// doi.org/10.1186/s13047-015-0067-8

12. Al Abduwani J, ZilinSkiene L, Colley S, Ahmed S (2016) Cone beam CT paranasal sinuses versus standard multidetector and low dose multidetector CT studies. Am J Otolaryngol 37(1):59-64. https://doi.org/10.1016/j.amjoto.2015.08.002

13. Haridas H, Mohan A, Papisetti S, Ealla KK (2016) Computed tomography: will the slices reveal the truth. J Int Soc Prev Community Dent 6(Suppl 2):S85-S92. https://doi.org/10.4103/ 2231-0762.189734

14. McCollough CH, Bruesewitz MR, Kofler JM Jr (2006) CT dose reduction and dose management tools: overview of available options. Radiographics : Rev Publ Radiol Soc North Am Inc 26(2): 503-512. https://doi.org/10.1148/rg.262055138

15. Kalra MK, Maher MM, Toth TL et al (2004) Techniques and applications of automatic tube current modulation for CT. Radiology 233(3):649-657. https://doi.org/10.1148/radiol.2333031150

16. Scarfe WC, Farman AG (2008) What is cone-beam CT and how does it work? Dent Clin N Am 52(4):707-730, v. https://doi.org/10. 1016/j.cden.2008.05.005 
17. De Smet E, De Praeter G, Verstraete KL, Wouters K, De Beuckeleer L, Vanhoenacker FM (2015) Direct comparison of conventional radiography and cone-beam $\mathrm{CT}$ in small bone and joint trauma. Skelet Radiol 44(8):1111-1117. https://doi.org/10.1007/s00256015-2127-3

18. Bechara BB, Moore WS, McMahan CA, Noujeim M (2012) Metal artefact reduction with cone beam CT: an in vitro study. Dentomaxillo fac Radiol 41(3):248-253. https://doi.org/10.1259/ $\mathrm{dmfr} / 80899839$

19. Meilinger M, Schmidgunst C, Schutz O, Lang EW (2011) Metal artifact reduction in cone beam computed tomography using forward projected reconstruction information. Z Med Phys 21(3):174182. https://doi.org/10.1016/j.zemedi.2011.03.002

20. Richter M, Seidl B, Zech S, Hahn S (2014) PedCAT for 3D-imaging in standing position allows for more accurate bone position (angle) measurement than radiographs or CT. Foot Ankle Surg : Off J Eur Soc Foot and Ankle Surg 20(3):201-207. https://doi. org/10.1016/j.fas.2014.04.004

21. Edlund R, Skorpil M, Lapidus G, Backlund J (2016) Cone-beam CT in diagnosis of scaphoid fractures. Skelet Radiol 45(2):197204. https://doi.org/10.1007/s00256-015-2290-6

22. Vanhoenacker FM, Desimpel J (2017) Cone beam CT of trauma of small bones and joints. Semin Musculoskelet Radiol 21(3):290302. https://doi.org/10.1055/s-0037-1602405

23. Osgood GM, Thawait GK, Hafezi-Nejad N, et al. (2017) Image Quality of Cone Beam Computed Tomography for Evaluation of Extremity Fractures in the Presence of Metal Hardware: Visual Grading Characteristics Analysis. Br J Radiol :20160539. doi: https://doi.org/10.1259/bjr.20160539

24. Dabbaghi A, Nikkerdar N, Bayati S, Golshah A (2016) Rare appearance of an odontogenic myxoma in cone-beam computed tomography: a case report. J Dent Res Dent Clin Dent Prospects 10(1):65-68. https://doi.org/10.15171/joddd.2016.010
25. Hunter AK, Muller S, Kalathingal SM, Burnham MA, Moore WS (2012) Evaluation of an ameloblastic fibro-odontoma with cone beam computed tomography. Tex Dent J 129(6):619-624

26. Araki M, Kameoka S, Matsumoto N, Komiyama K (2007) Usefulness of cone beam computed tomography for odontogenic myxoma. Dentomaxillofacial Radiol 36(7):423-427. https://doi. org $/ 10.1259 / \mathrm{dmfr} / 85361774$

27. Suojarvi N, Haapamaki V, Lindfors N, Koskinen SK (2017) Radiocarpal injuries: cone beam computed tomography arthrography, magnetic resonance arthrography, and arthroscopic correlation among 21 patients. Scand J Surg 106(2):173-179. https://doi.org/10.1177/1457496916659226

28. Schafer S, Nithiananthan S, Mirota DJ et al (2011) Mobile C-arm cone-beam CT for guidance of spine surgery: image quality, radiation dose, and integration with interventional guidance. Med Phys 38(8):4563-4574. https://doi.org/10.1118/1.3597566

29. Cazzato RL, Garnon J, Tsoumakidou G et al (2017) Percutaneous image-guided screws meditated osteosynthesis of impeding and pathological/insufficiency fractures of the femoral neck in non-surgical cancer patients. Eur J Radiol 90:1-5. https://doi.org/10.1016/j. ejrad.2017.02.022

30. Kroes MW, Busser WM, Hoogeveen YL, de Lange F, Schultze Kool LJ (2017) Laser guidance in C-arm cone-beam CT-guided radiofrequency ablation of osteoid osteoma reduces fluoroscopy time. Cardiovasc Intervent Radiol 40(5):728-734. https://doi.org/ 10.1007/s00270-016-1533-9

31. Thakor AS, Patel PA, Gu R, Rea V, Amaral J, Connolly BL (2016) MR cone-beam CT fusion image overlay for fluoroscopically guided percutaneous biopsies in pediatric patients. Pediatr Radiol 46(3): 407-412. https://doi.org/10.1007/s00247-015-3479-5

32. Tselikas L, Joskin J, Roquet $\mathrm{F}$ et al (2015) Percutaneous bone biopsies: comparison between flat-panel cone-beam CT and CT-scan guidance. Cardiovasc Intervent Radiol 38(1):167-176. https://doi. org/10.1007/s00270-014-0870-9 